media were clear; the right pupil was active and the left was sluggish. There was occasional divergent strabismus. The right optic disc was swollen and the edges were blurred by effusion which here and there obscured the vessels. The veins were full and tortuous; the arteries were smaller than normal and difficult to see. The retina in the region of the disc and yellow spot was cedematous. A few small striate hæmorrhages were visible along the course of the vessels near the disc. In the macular region were about four well-marked soft grey patches showing hæmorrhagic borders. In between the patches were a few small punctate hæmorrhages. The left optic disc was not so swollen and the edges were better defined. There was less cedema of the retina and the veins were less full and tortuous, while the arteries were more visible and larger. The hæmorrhages were fewer and the grey patches at the macula were fewer (two). Blood examination gave the following result: hæmoglobin, 10 per cent. ; red blood corpuscles, 1,012,500 per cubic millimetre; and white blood corpuscles, 8200 per cubic millimetre. The colour index was 0.44 . The blood was examined on July 5th, the result being as follows: hæmoglobin, 10 per cent. ; and red blood corpuscles, 1,392,000 per cubic millimetre. Stained films showed great variety in the size of the red cells, some very large, some very small, some evidently degenerating, many poikilocytes, a very few nucleated red cells, some normoblasts (one with a nucleus showing mitosis), and one or two megaloblasts. There was an apparent increase in blood plates. There was no apparent increase in the leucocytes. Some increase in transitional forms was noted as well as some atypical myelocytes. On Angust 4th the blood was again examined with the following result: hæmoglobin, 54 per cent. ; red blood corpuscles, $3,000,000$ per cubic millimetre and white blood corpuscles, 7080 per cubic millimetre. Stained films showed a few poikilocytes and microcytes but no nucleated red cells. The red cells were of fairly uniform size and stained evenly. No abnormal leucocytes were observed. The patient was discharged on August 6th. She unfortunately left the hospital without having her vision tested but the deterioration was evidently not such as to cause her any inconvenience.

CASE 5.-The patient, a girl, aged 19 years, was admitted to hospital on Jan. 4th, 1899. The general health had been indifferent for two months. The sight had been failing for a month ; several times a day it would get "misty" for a second or two and then clear up again. On admission the mucous membranes and skin were very pale. The patient had suffered from breathlessness and constipation. There was a basal murmur. The pupils were normal.

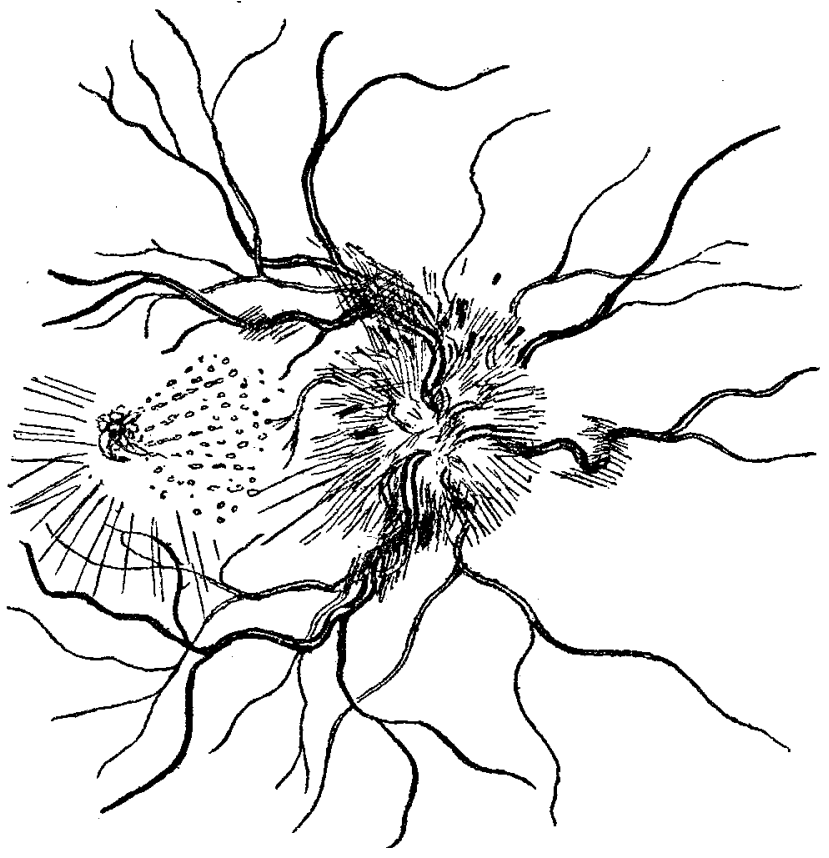

Right fundus of Case 5 .

Marked papillitis was present with a few striate hæmorrhages near the edges of the swollen and ill-defined discs. The swelling of the discs $=+6 \mathrm{D}$. There was a fan shaped arrangement of white degenerative lines and spots extending between the yellow spots and discs. The fover were occupied by a dark brown network situated superficially to the white lines. R.V. $=\frac{6}{12}$ c. +4.5 D. ; L.V. $=\frac{6}{1}$ c. +5 D. The treatment was the same as that carried out in Case 1. On Jan. 10th the blood was examined, the result being as follows: hæmoglobin, 50 per cent.; and red blood corpuscles, $3,400,000$ per cubic millimetre. The colour index was 0.7 . On the 31 st R.V. $=\frac{6}{8}$ c. $\frac{+4.5}{+0.50} \phi_{10}$ L.V. $=\frac{6}{12}$ c. +6.5 D. The fundi were in statu quo (vide illustration). On Feb. 16th R.V. $=\frac{6}{6}$ c. $\frac{+5 \text { D. }}{+0.50 \phi} ;$ L.V. $=\frac{6}{8}$ c. +6 D. There were much less swelling of the discs and very little effusion into the retinæ. The degenerative changes near the yellow spot were in statu quo. The patient was discharged on May 4th.

Birmingham.

\section{FASTING IN THERAPEUTICS.}

\section{BX JOHN HADDON, M.A., M.D. EDIN.}

HAVING had occasion to study diet my attention has been directed to fasting as a therapeutic agent and the following case seems worthy of record.

The patient was a man, aged 65 years, who had been a hard drinker and a good eater all his life, working on contracts. He was much crushed and nearly drowned by scaffolding falling upon him. His life was for some time despaired of but he recovered. When I saw him seven years after the accident he weighed 18 stones, was crippled on one foot, and walked with a stick very slowly. He could not sleep in the night from coughing and spitting, passed urine every hour, and conld hardly turn in bed from a stabbing pain in the side. He conld not dress himself and was altogether in a pitiable condition. Having seen him I promised him that if he would follow my advice he would renew his youth. He was a man of powerful will and he said that he would do anything to get well.

I put him upon a little fruit twice daily. In five days he lost ten pounds in weight and he could dress himself and lace his boots which he had not done for years. As he lost weight his vigour increased and he began to work in his garden and to take long walks. All his troublesome symptoms left him and he could sleep like a child from 9 P.M. to $4 \mathrm{~A}$.M. without waking. He had to get new clothes to suit his reduced size and in November (he began in June to restrict his diet) declared that he felt as well as ever he did and were it not for the damage he had received in the accident he might resume work as before. On Nov. 10th 1 saw him wheeling up a hill a barrowful of potatoes which he had himself dug out in the field.

The change in his pulse was remarkable (Figs. 1 and 2). I never felt or saw a pulse so irregular and intermittent in character at first but it gradually improved and became fairly regular which the sphygmographic tracings show very clearly.

FIG. 1.

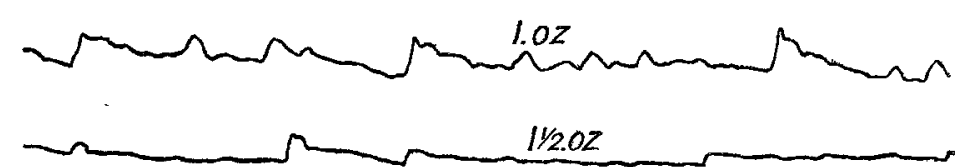

Pulse tracing, June 16th, 1903. Pressure one ounce and one and a-half ounces.

FIG. 2.

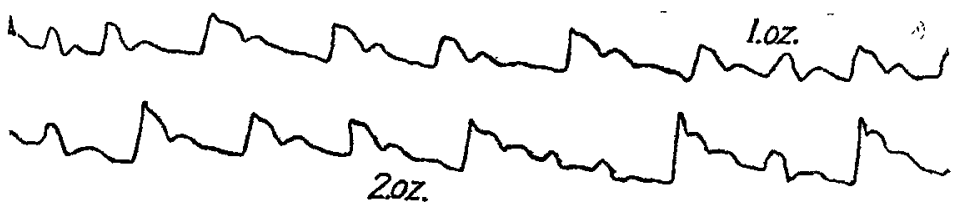

Pulse tracing, Oct. 18th, 1903. Pressure one ounce and two ounces.

He said he was neither hungry nor thirsty on the fruit diet. He now eats only about a quarter of what he did formerly and when the weather prevents him working or walking he at once gains weight.

This case seems deserving of attention from the marvellous change produced by abstinence and may encourage us to try a partial or perfect fast in suitable cases.

Denholm, N.B. 